\title{
Physical Characterization of meso-Erythritol as a Crystalline Bulking Agent for Freeze-Dried Formulations
}

\author{
Kahori Fujii, ${ }^{* a, b}$ Ken-ichi Izutsu, ${ }^{c}$ Migiwa Kume, ${ }^{a}$ Takeshi Yoshino, ${ }^{a}$ Yasuo Yoshihashi, ${ }^{a}$ \\ Kiyohiko Sugano, ${ }^{a}$ and Katsuhide Terada ${ }^{a}$ \\ ${ }^{a}$ Faculty of Pharmaceutical Sciences, Toho University; 2-2-1 Miyama, Funabashi, Chiba 274-8510, Japan: ${ }^{b}$ R\&D \\ Laboratories, POLA Pharma Inc.; 560 Kashio-cho, Totsuka-ku, Yokohama 244-0812, Japan: and ${ }^{c}$ National Institute \\ of Health Sciences; 1-18-1 Kamiyoga, Setagaya-ku, Tokyo 158-8501, Japan. \\ Received September 28, 2014; accepted February 18, 2015
}

The purpose of this study was to identify and characterize new crystalline bulking agents applicable to freeze-dried pharmaceuticals. Thermal analysis of heat-melt sugar and sugar alcohol solids as well as their frozen aqueous solutions showed high crystallization propensity of meso-erythritol and D-mannitol. Experimental freeze-drying of the aqueous meso-erythritol solutions after their cooling by two different methods (shelf-ramp cooling and immersion of vials into liquid nitrogen) resulted in cylindrical crystalline solids that varied in appearance and microscopic structure. Powder X-ray diffraction and thermal analysis indicated different crystallization processes of meso-erythritol depending on the extent of cooling. Cooling of the frozen meso-erythritol solutions at temperatures lower than their $T_{\mathrm{g}}{ }^{\prime}$ (glass transition temperature of maximally freeze-concentrated phase, $-59.7^{\circ} \mathrm{C}$ ) induced a greater number of nuclei in the highly concentrated solute phase. Growth of multiple meso-erythritol anhydride crystals at around $-40^{\circ} \mathrm{C}$ explains the powder-like fine surface texture of the solids dried after their immersion in liquid nitrogen. Contrarily, shelf-ramp cooling of the frozen solution down to $-40^{\circ} \mathrm{C}$ induced an extensive growth of the solute crystal from a small number of nuclei, leading to scale-like patterns in the dried solids. An early transition of the freezing step into primary drying induced collapse of the non-crystalline region in the cakes. Appropriate process control should enable the use of meso-erythritol as an alternative crystalline bulking agent in freeze-dried formulations.

Key words meso-erythritol; crystallization; freeze-drying; sugar alcohol; thermal analysis

Freeze-drying is a popular method for formulating various therapeutic proteins, liposomes, and antibiotics that are not sufficiently stable during storage in aqueous solutions or during drying at high temperatures. ${ }^{1,2}$ The process is also used to prepare amorphous solid formulations that foster better dissolution rates and bioavailability of poorly soluble pharmaceuticals. Various active pharmaceutical ingredients (APIs) and excipients composing the freeze-dried solids are either in their amorphous or crystalline states. ${ }^{3)}$ The component crystallinity is determined by various factors including their intrinsic properties, co-solute compositions, and thermal history of the process. ${ }^{4}$ )

Many freeze-dried formulations contain amorphous or crystalline bulking agents to prevent loss of the APIs during handling and/or provide better appearance. Some disaccharides (e.g., sucrose and trehalose) form glass-state amorphous dried solids that protect the conformation of embedded proteins and supramolecular assembly of liposomes from dehydration-induced irreversible conformational changes during the process and from their chemical degradation during storage. ${ }^{5,6)}$ Some excipients (e.g., D-mannitol and glycine) are used to obtain superior appearance of stable crystalline solids, although they do not show protein-stabilizing effects. ${ }^{7)}$ They crystallize mainly during the freezing step of the lyophilization process. The crystallized bulking agents allow faster primary drying (ice sublimation) at higher product temperatures without physical collapse that often occurs during drying of freeze-concentrated amorphous components. One potential drawback with the use of mannitol, however, is its varied crystalline forms, including mannitol hemihydrate, in the freeze-dried solids. ${ }^{8)} \mathrm{Re}$ - lease of the crystallization water from the hemihydrate crystal induces undesirable physical and chemical changes of colyophilized APIs during storage. ${ }^{7,9,10)}$ Freeze-drying of glycine also leads to the formation of multiple crystal forms. ${ }^{11)}$ Therefore, the physical property (e.g., crystallinity and crystal polymorph) of bulking agents is a significant factor in the design of freeze-dried formulations that are appropriate for particular APIs and administration routes. ${ }^{9)}$ Exposure of the frozen solution to high temperatures (annealing) is often performed to complete excipient crystallization. ${ }^{12}$ Some combinations of different types of excipients (e.g., sucrose and mannitol) are receiving increased attention for use in obtaining microporous freeze-dried solids composed of the protein-stabilizing glass region dispersed in the physically stable crystal skeleton. ${ }^{13)}$

The purpose of this study was to find and characterize new crystalline bulking agents applicable for freeze-dried pharmaceuticals. Crystallization propensity of various sugars and sugar alcohols, often used as pharmaceutical excipients or food additives, was studied by thermal analysis of heatmelt solids and frozen aqueous solutions. We also performed experimental freeze-drying of meso-erythritol that showed a high propensity to crystallize in the screening described above. Erythritol is a naturally occurring four-carbon sugar alcohol present in various fruits, fermented food, and body fluids of humans and animals. An EU Scientific Committee on Food review and generally recognized as safe (GRAS) registration by the Food and Drug Administration (FDA) supports wide use of erythritol, manufactured mainly by glucose fermentation, as a low calorie sugar substitute in foods and beverages. $^{14-16)}$ Some animal studies indicated no significant 
gastrointestinal effects found at doses up to $1000 \mathrm{mg} / \mathrm{kg}$ body $\mathrm{wt} / \mathrm{d}$ in animals. ${ }^{17)}$ Erythritol is also used as a bulking or sweetening agent in orally administered pharmaceuticals (e.g., tablet and syrup). ${ }^{18)}$ Erythritol as well as various sugars and sugar alcohols protect proteins from thermal denaturation in aqueous solutions. ${ }^{19)}$ Its high solubility in aqueous solutions may also be favorable for preparing freeze-dried formulations. $^{20)}$

\section{Experimental}

Materials All chemicals used in this study were purchased from various following commercial sources: L-arabinose, sucrose, D-sorbitol, and D-trehalose dihydrate (SigmaAldrich Co.); L-arabitol, D-mannitol, palatinit, xylitol, lactitol monohydrate, and myo-inositol (Wako Pure Chemical Industries, Ltd.); maltitol (Hayashibara Biochemical Laboratories, Inc., Japan); and meso-erythritol (Tokyo Chemical Industry Co.).

Crystallization Propensity of Heat-Melt Sugars and Sugar Alcohols The thermal analysis of powders and frozen solutions was performed using a differential scanning calorimeter (DSC, DSC7, Perkin-Elmer). Alumina was used as a control for the thermal scan. PYRIS Ver. 3.8 software was used to process the data. Crystallization propensity of the sugars and sugar alcohols were studied using aliquots (approximately $10 \mathrm{mg}$ ) of powder in hermetically sealed pans. The solids were heated at $10^{\circ} \mathrm{C} / \mathrm{min}$ to $190^{\circ} \mathrm{C}$ (D-mannitol), $210^{\circ} \mathrm{C}$ (sucrose), or $180^{\circ} \mathrm{C}$ (other excipients). Then, the heat-melt solids were cooled in the DSC furnace down to $-20^{\circ} \mathrm{C}$ at $10^{\circ} \mathrm{C} / \mathrm{min}$ before the second heating scan at $10^{\circ} \mathrm{C} / \mathrm{min}$. The samples were held isothermally for $1 \mathrm{~min}$ between the steps. Crystallization of the solutes in frozen solutions was also evaluated by thermal analysis. Aliquots $(10 \mu \mathrm{L})$ of the solution $(100 \mathrm{mg} / \mathrm{mL})$ in aluminum cells were cooled from $25^{\circ} \mathrm{C}$ to $-70^{\circ} \mathrm{C}$ at $10^{\circ} \mathrm{C} /$ min before they were subjected to heating scans at $5^{\circ} \mathrm{C} / \mathrm{min}$ to reach $25^{\circ} \mathrm{C}$.

Physical Characterization of meso-Erythritol Frozen Solutions Thermal analysis of frozen solutions was conducted using a differential scanning calorimeter (DSC Q-10, TA Instruments) with Universal Analysis 2000 software (TA Instruments). Aliquots $(10 \mu \mathrm{L})$ of aqueous meso-erythritol solution $(100 \mathrm{mg} / \mathrm{mL})$ in aluminum cells were cooled from $25^{\circ} \mathrm{C}$ to $-40,-50,-60$, or $-70^{\circ} \mathrm{C}$ at $10^{\circ} \mathrm{C} / \mathrm{min}$, and scanned by heating to $25^{\circ} \mathrm{C}$ at $5^{\circ} \mathrm{C} / \mathrm{min}$. Some frozen solutions were held at $-40^{\circ} \mathrm{C}$ for $10 \mathrm{~min}$ before the heating scan. The $T_{\mathrm{g}}{ }^{\prime} \mathrm{s}$ (glass transition temperature of maximally freeze-concentrated phase) of frozen meso-erythritol solution $(100 \mathrm{mg} / \mathrm{mL})$ was determined from the maximum inflection point of the discontinuities in the heat flow curves scanned from $-80^{\circ} \mathrm{C}$. Freezing of ice concentrates non-ice solutes until the increasing viscosity prevents further ice growth. Glass transition of the maximally freeze-concentrated phase is considered to show large heat flow change at particular temperature $\left(T_{\mathrm{g}}{ }^{\prime}\right)$ during heating thermal scan of the frozen solution, while there are some debates on the definition. ${ }^{3)}$

X-Ray diffraction analyses of frozen meso-erythritol solutions $(100 \mathrm{mg} / \mathrm{mL})$ were performed using a simultaneous X-ray diffractometry (XRD)-DSC system and a temperaturecontrolled XRD system. A simultaneous XRD-DSC system (SmartLab-DSC, Rigaku, $\mathrm{Cu} K \alpha$ radiation: $45 \mathrm{kV} / 200 \mathrm{~mA}$ ) was used to obtain diffraction patterns and thermal profiles of frozen solutions placed on aluminum pans during cooling to $-40^{\circ} \mathrm{C}$, holding at $-40^{\circ} \mathrm{C}(180 \mathrm{~min})$, and subsequent heating at $2{ }^{\circ} \mathrm{C} / \mathrm{min}$. A temperature-controlled XRD system (Ultima IV, Rigaku, $\mathrm{Cu} K \alpha$ radiation: $40 \mathrm{kV} / 40 \mathrm{~mA}$ ) was used to obtain diffraction patterns $\left(10^{\circ}<2 \theta<42^{\circ}\right.$ at $\left.10 \% \mathrm{~min}\right)$ of frozen solutions during cooling to $-65^{\circ} \mathrm{C}$, holding at $-65^{\circ} \mathrm{C}$ (approximately $6 \mathrm{~min}$ ), and subsequent heating at $2^{\circ} \mathrm{C} / \mathrm{min}$.

Freeze-Drying Microscope (FDM) Analysis We observed the behavior of frozen meso-erythritol solutions under vacuum using a freeze-drying microscope system (Lyostat2 system, Linkam Scientific Instruments) with an optical microscope (Model BX51, Olympus Co.). The cell temperature sensor was calibrated using the melting temperatures of ice, naphthalene crystal, and eutectic $\mathrm{NaCl}$ crystal as standards. Aqueous solutions $(2 \mu \mathrm{L})$ sandwiched between cover slips ( $70 \mu \mathrm{m}$ apart) were cooled to $-70^{\circ} \mathrm{C}$ at $10^{\circ} \mathrm{C} / \mathrm{min}$ and then maintained at $-70^{\circ} \mathrm{C}$ for $5 \mathrm{~min}$. The observation field was moved during the scan to follow the ice sublimation front. The collapse temperature $\left(T_{\mathrm{c}}\right)$ of the frozen solution was determined from the appearance of translucent dots behind the ice sublimation interface. Some frozen solutions $\left(-70^{\circ} \mathrm{C}\right)$ were heat-treated at $-30^{\circ} \mathrm{C}$ for $10 \mathrm{~min}$ (annealing) before their second heating scan from $-70^{\circ} \mathrm{C}$ to $-50^{\circ} \mathrm{C}$ under vacuum $\left(1{ }^{\circ} \mathrm{C} /\right.$ min, approximately 0.015 mbar). The drying process of the frozen solution was also observed during a heating scan from $-12^{\circ} \mathrm{C}\left(1^{\circ} \mathrm{C} / \mathrm{min}, 2.2 \mathrm{mbar}\right)$. The eutectic temperature $\left(T_{\mathrm{eu}}\right)$ of the frozen solution was obtained from changes in the gross morphology of the frozen phase to produce a more liquid appearance.

Freeze-Drying A freeze-drier (Freezone-6, Labconco) was used for lyophilization. Aqueous solutions $(2 \mathrm{~mL})$ in flatbottom glass vials were placed on the lyophilizer shelves. The shelves were cooled to $-40^{\circ} \mathrm{C}$ at $0.5^{\circ} \mathrm{C} / \mathrm{min}$ and then maintained at this temperature for $2 \mathrm{~h}$. Other solutions were frozen by immersing the vials in liquid nitrogen for about $5 \mathrm{~min}$ before they were transferred to the pre-cooled lyophilizer shelves. The primary and secondary drying of the frozen solutions were performed at $-40^{\circ} \mathrm{C}(30 \mathrm{~h})$ and $35^{\circ} \mathrm{C}(4 \mathrm{~h})$, respectively, under reduced pressure $(0.03 \mathrm{mbar})$. Some solutions were shelf-cooled to $-32^{\circ} \mathrm{C}$ before vacuum drying at $-32^{\circ} \mathrm{C}$ $(30 \mathrm{~h})$ and $35^{\circ} \mathrm{C}(4 \mathrm{~h})$. The shelves were heated at $0.2^{\circ} \mathrm{C} / \mathrm{min}$ between the thermal steps. The vials were closed with rubber stoppers under a vacuum.

Characterization of Freeze-Dried Solids Morphological study of a roughly crushed freeze-dried solid surface was performed using scanning electron microscopy (SEM) (VE-7800, Keyence Co.). Prior to imaging, mounted samples were sputter-coated with gold. The samples were exposed to a $20-\mathrm{kV}$ acceleration voltage at $10 \mathrm{~Pa}$. The powder X-ray diffraction patterns of the solids were obtained at room temperature using a D8 DISCOVER with general area detector diffraction solution, Bruker AXS) with $\mathrm{Cu} K \alpha$ radiation at $40 \mathrm{kV} / 40 \mathrm{~mA}$. The samples were scanned in the area of $10^{\circ}<2 \theta<30^{\circ}$.

The thermal analysis of freeze-dried solids was performed using a differential scanning calorimeter. The melting points of the freeze dried solids were studied using aliquots $(10 \mathrm{mg})$ of powder in hermetically sealed pans. The solids were then heated at $10^{\circ} \mathrm{C} / \mathrm{min}$ to $180^{\circ} \mathrm{C}$.

\section{Results}

Crystallization Propensity of Sugars and Sugar Alco- 
hols Sugars and sugar alcohols showed varied propensity for crystallization after heat-melting (Table 1). Crystallization exotherms of some sugar alcohols were observed during the cooling process of the heat-melt (D-mannitol, meso-erythritol, and myo-inositol) and/or the second heating process (L-arabitol, meso-erythritol, and myo-inositol). These solids showed crystal melting endotherms again in the second heating scans. Absence of the peaks in other heat-melt sugars and sugar alcohols indicated maintenance of the amorphous states. The crystallization profiles were categorized into three groups following a study by Baird et al. ${ }^{21)}$ Class (I) - crystallized during cooling of the heat-melt, class (II) — crystallized during reheating of the heat-melt, and class (III) - no apparent crystallization in either during cooling or reheating scans. mesoErythritol and myo-inositol are categorized as Classes I and II since they showed crystallization peaks both during cooling of the heat-melt and reheating.

Thermal analysis of frozen aqueous sugar and sugar alcohol solutions also showed varied crystallization propensities. Frozen D-mannitol and meso-erythritol solutions showed solute crystallization exotherms during heating scans. An endotherm peak also appeared before ice melting in the frozen mesoerythritol solution $\left(-8^{\circ} \mathrm{C}\right.$ to $\left.-7^{\circ} \mathrm{C}\right)$. Absence of thermal peaks demonstrates amorphous freeze-concentrated states of other solutes. The gradual shifts of DSC curves above $T_{\mathrm{g}}{ }^{\prime}$ of the frozen solutions are also recognized as typical changes due to melting of ice surrounding the non-crystalline solute phases. ${ }^{22)}$ These results indicate high propensities of D-mannitol and meso-erythritol to crystallize in the dried state and frozen solutions.

Physical Characterization of Frozen meso-Erythritol Solutions We further studied the physical properties of frozen meso-erythritol solutions and possible application of sugar alcohols as crystalline bulking agents in freeze-dried formulations. Figure 1 shows DSC curves of frozen meso-erythritol solutions obtained in the heating scans after being cooled to various temperatures $\left(-70^{\circ} \mathrm{C}\right.$ to $\left.-40^{\circ} \mathrm{C}\right)$. The heating scan from $-70^{\circ} \mathrm{C},-60^{\circ} \mathrm{C}$, and $-50^{\circ} \mathrm{C}$ showed one exotherm peak $\left(-36^{\circ} \mathrm{C}\right.$ to $-21^{\circ} \mathrm{C}$ : solute crystallization) and two endotherm peaks at $-7^{\circ} \mathrm{C}$ and $0^{\circ} \mathrm{C}$. Contrarily, the heating scan of the frozen solution from $-40^{\circ} \mathrm{C}$ showed only the large ice melting peak. Holding the frozen solution at $-40^{\circ} \mathrm{C}$ for $10 \mathrm{~min}$ before the heating scan induced a small endotherm at approximately $-10^{\circ} \mathrm{C}$. These thermal profiles indicate fast solute crystallization only after cooling to lower temperatures. Heating scan of the frozen meso-erythritol solution from $-80^{\circ} \mathrm{C}$ indicated $T_{\mathrm{g}}{ }^{\prime}$ at $-59.7 \pm 0.5^{\circ} \mathrm{C}$ (data not shown).

Figures 2, 3 show diffraction patterns of frozen mesoerythritol solutions simultaneously obtained by a XRD-DSC system and a temperature-controlled XRD system. The XRD-DSC analysis showed, in addition to the large peaks of the hexagonal ice crystals, appearance and slow growth of new diffraction peaks at $15^{\circ}, 19^{\circ}, 20^{\circ}, 26.5^{\circ}, 28^{\circ}$, and $30^{\circ}$ during holding the frozen solution at $-40^{\circ} \mathrm{C}^{23-25}$ ) (Fig. 2). These peaks, observed at positions identical to those of mesoerythritol anhydrate, grew slowly during the heating up to $-10^{\circ} \mathrm{C}^{26)}$ These peaks disappeared above the first endotherm temperature $\left(-8^{\circ} \mathrm{C}\right)$. Further heating of the frozen solution resulted in absence of the ice crystal peaks (data not shown). Thus, the two endotherms in the heating scan could repre-

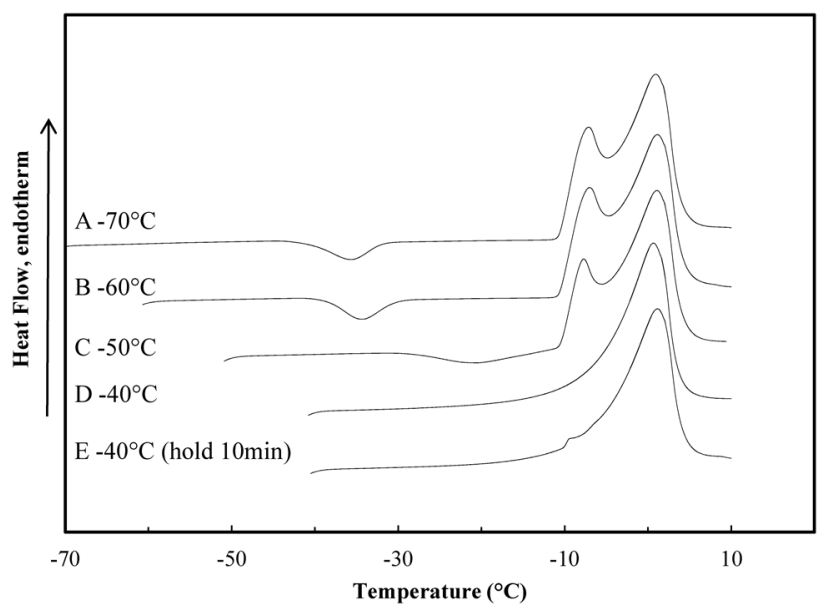

Fig. 1. DSC Curves of Frozen meso-Erythritol Solutions $(100 \mathrm{mg} / \mathrm{mL})$ Obtained by Heating Thermal Scans from Various Temperatures

(A) $-70^{\circ} \mathrm{C}$, (B) $-60^{\circ} \mathrm{C},(\mathrm{C})-50^{\circ} \mathrm{C}$, and (D, E) $-40^{\circ} \mathrm{C}$.

Table 1. Thermal Properties of Sugars and Sugar Alcohols

\begin{tabular}{|c|c|c|c|c|c|c|}
\hline \multirow{3}{*}{ Excipients } & \multicolumn{5}{|c|}{ Solids } & \multirow{3}{*}{$\begin{array}{c}\text { Frozen solution } \\
\begin{array}{c}\text { Crystallization temp. } \\
\left({ }^{\circ} \mathrm{C}\right)\end{array} \\
\text { Heating }\end{array}$} \\
\hline & \multicolumn{2}{|c|}{$\begin{array}{l}\text { Melting temp. } \\
\left({ }^{\circ} \mathrm{C}\right)\end{array}$} & \multicolumn{2}{|c|}{$\begin{array}{c}\text { Crystallization temp. } \\
\left({ }^{\circ} \mathrm{C}\right)\end{array}$} & \multirow{2}{*}{$\begin{array}{c}\text { Crystallization } \\
\text { propensity* }\end{array}$} & \\
\hline & 1 st run & 2nd run & Cooling & Heating & & \\
\hline L-Arabinose & $170.8 \pm 5.2$ & - & - & - & III & - \\
\hline Sucrose & $202.4 \pm 0.1$ & - & - & - & III & - \\
\hline L-Arabitol & $115.5 \pm 0.3$ & $112.2 \pm 4.6$ & - & $85.3 \pm 5$ & II & - \\
\hline D-Mannitol & $179.5 \pm 1.8$ & $179.5 \pm 1.7$ & $112.4 \pm 3.7$ & - & I & $-26.2 \pm 2.8$ \\
\hline Palatinit & $105 \pm 4.2$ & - & - & - & III & - \\
\hline Maltitol & $159.2 \pm 5.1$ & - & - & - & III & - \\
\hline D-Sorbitol & $103.8 \pm 7.2$ & - & - & - & III & - \\
\hline D-Trehalose dihydrate & $99 \pm 6.1$ & - & - & - & III & - \\
\hline meso-Erythritol & $133.2 \pm 1.5$ & $133.7 \pm 1.6$ & $15.5 \pm 0(n=2)$ & $34.3(n=1)$ & I, II & $-34.1 \pm 0.6$ \\
\hline Xylitol & $107.2 \pm 0.5$ & - & - & - & III & - \\
\hline Lactitol monohydrate & $108.9 \pm 4.2$ & - & - & - & III & - \\
\hline myo-Inositol & $239.3 \pm 0.7$ & $239.8 \pm 0.3$ & $189.5 \pm 0.2$ & $196.8 \pm 0.8$ & I, II & - \\
\hline
\end{tabular}

Average \pm S.D. $(n=3)$. - , No peak was observed. ${ }^{*}$ Crystallization propensity of the excipients were categorized following the method by Baird $e t$ al. ${ }^{21)}$ 


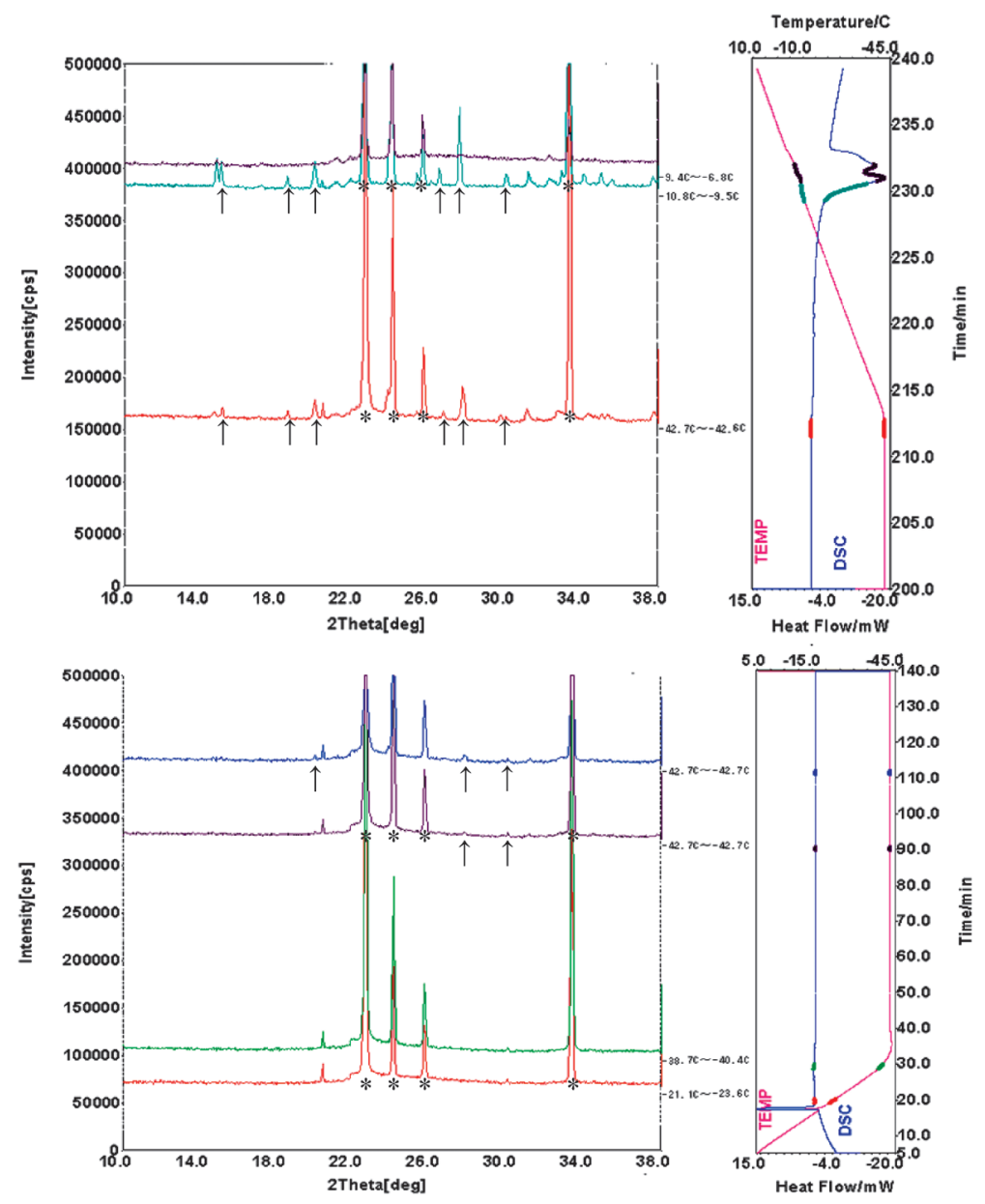

Fig. 2. Simultaneous XRD-DSC Measurement Plots of a Frozen $100 \mathrm{mg} / \mathrm{mL}$ meso-Erythritol Solution Obtained during Cooling Down to $-40^{\circ} \mathrm{C}$, Holding at $-40^{\circ} \mathrm{C}(180 \mathrm{~min})$, and Subsequent Heating at $2^{\circ} \mathrm{C} / \mathrm{min}$

Asterisks $(*)$ denote diffraction peaks of hexagonal ice crystals. Arrows $(\uparrow)$ denote peaks appeared during heating.

sent melting of the solute crystal (eutectic melting, $-8^{\circ} \mathrm{C}$ to $-7^{\circ} \mathrm{C}$ ) and ice (around $0^{\circ} \mathrm{C}$ ). A temperature-controlled XRD was used to elucidate physical changes in the frozen solution cooled to a lower temperature $\left(-65^{\circ} \mathrm{C}\right.$, Fig. 3). The diffraction pattern showed rapid appearance of the solute crystal peaks at around $-40^{\circ} \mathrm{C}$. Their peak positions were similar to those in the frozen solutions cooled to $-40^{\circ} \mathrm{C}$.

The primary drying process of the frozen meso-erythritol solutions $(100 \mathrm{mg} / \mathrm{mL})$ was studied by FDM analysis with and without prior annealing. Figure 4 shows microscopic images obtained at various temperatures. The heating scan of the frozen solution under vacuum without prior annealing induced significant loss of the solid structure from the sublimation interface (collapse) at -56 to $-52^{\circ} \mathrm{C}$ (Figs. 4A, B). Low $T_{\mathrm{g}}{ }^{\prime}$ of the frozen solution could explain the apparent morphology change at the amorphous concentrated solute region. Prior exposure of the frozen meso-erythritol solution to a higher temperature $\left(-30^{\circ} \mathrm{C}, 10 \mathrm{~min}\right)$ apparently improved physical stability of the solid phase (Figs. 4C-F). The annealed frozen solution allowed the ice sublimation without apparent change of the solid structure up to approximately $-10^{\circ} \mathrm{C}$ (Fig. 4E). The ice sublimation left a darker solid region in the FDM images. Increasing brightness of the frozen solution region and less clear sublimation boundary indicates melting of the eutectic solute at $T_{\text {eu }}\left(-7.3 \pm 0.3^{\circ} \mathrm{C}\right.$, Fig. $\left.4 \mathrm{~F}\right)$.

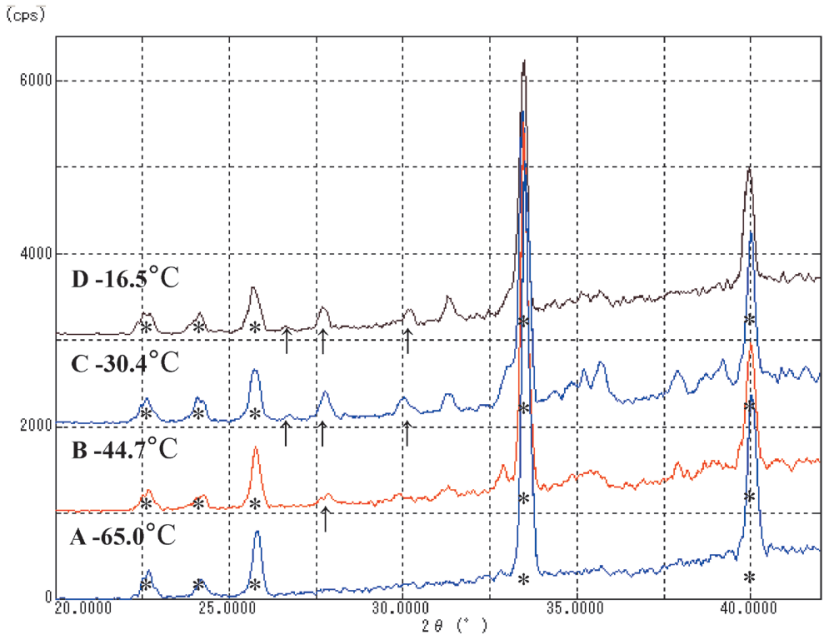

Fig. 3. Diffraction Patterns of Frozen $100 \mathrm{mg} / \mathrm{mL}$ meso-Erythritol Solution Obtained during the Heating Process by Temperature-Controlled XRD

Asterisks $(*)$ denote diffraction peaks of hexagonal ice crystals. Arrows $(\uparrow)$ denote peaks appeared during heating.

Physical Characterization of Freeze-Dried Solids The aqueous meso-erythritol solutions were lyophilized in several freezing methods to elucidate the physical changes during the 

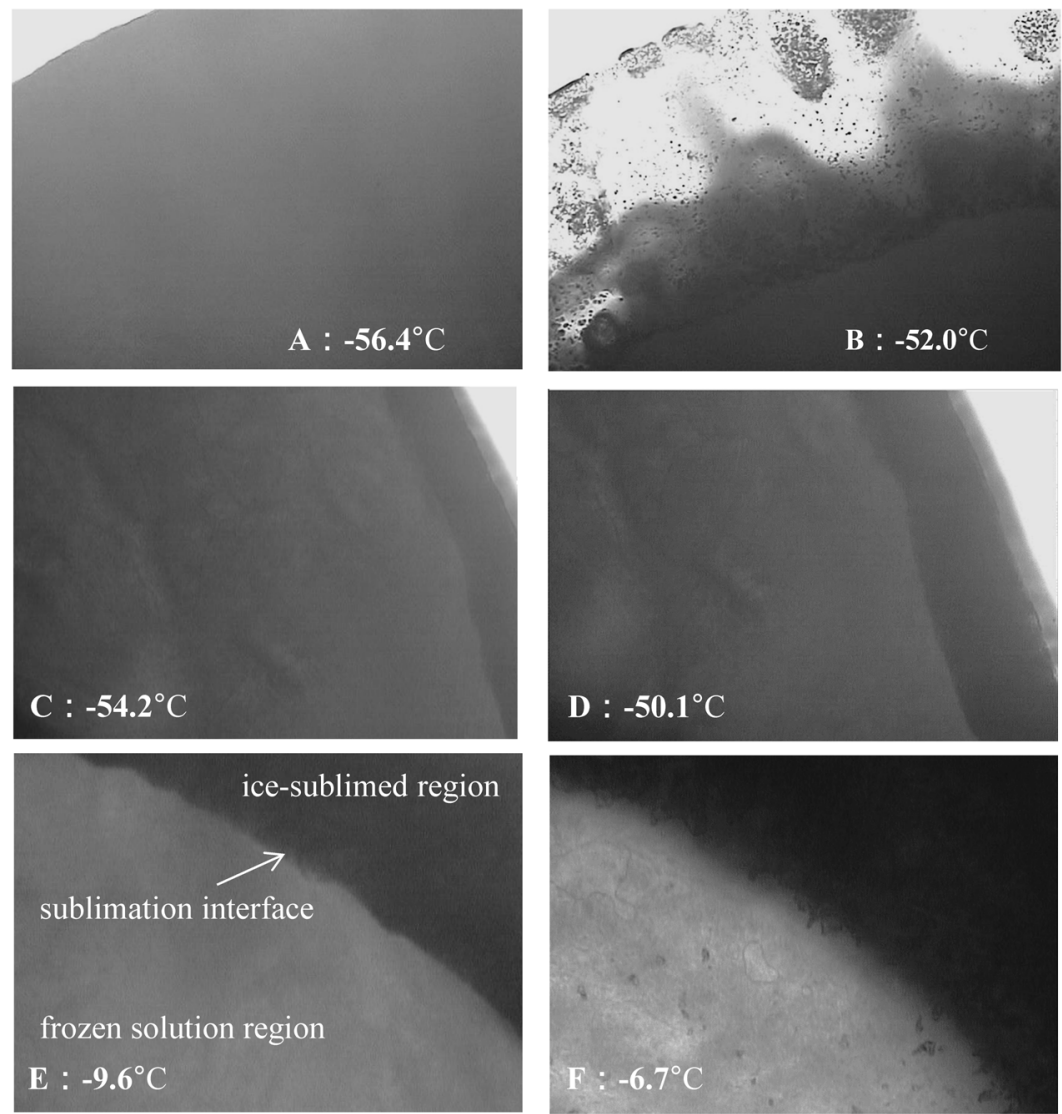

Fig. 4. FDM Analysis Images of Frozen meso-Erythritol Solutions $(100 \mathrm{mg} / \mathrm{mL})$ Obtained during Scans without (A, B) or with (C-F) Prior Annealing at $-30^{\circ} \mathrm{C}$

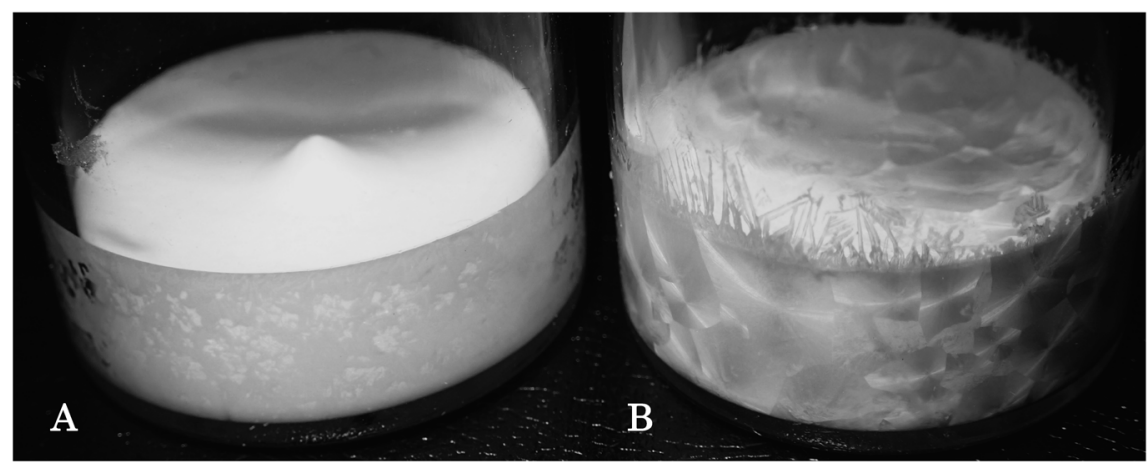

Fig. 5. Appearance of Lyophilized meso-Erythritol Solids Obtained by Drying of Aqueous Solutions (100 mg/mL) Frozen by Immersion in Liquid Nitrogen (A) and Shelf-Ramp Cooling (B)

process. Drying of meso-erythritol solutions after freezing by immersion in liquid nitrogen resulted in cylindrical solids with powder-like fine texture surfaces (Fig. 5A). On the other hand, solids dried after freezing on the lyophilizer shelves $\left(-40^{\circ} \mathrm{C}\right)$ showed scale-like patterns on the surface of the cakes (Fig. 5B). Variation in the meso-erythritol concentration $(50-200 \mathrm{mg} / \mathrm{mL})$ did not apparently affect structure of the resulting solids. Visual observation of the frozen solutions after their shelf-ramp cooling to -32 or $-40^{\circ} \mathrm{C}$ showed slowly appearing white dots that indicate regions with crystallized meso-erythritol (Fig. 6A). This crystal growth may explain the scale-like pattern in the dried solids. The frozen solutions experienced slower crystallization at higher shelf temperature $\left(-32^{\circ} \mathrm{C}\right)$. Starting the vacuum drying before completion of the crystallization resulted in a vermiculate appearance of solids with some structurally collapsed regions (Fig. 6B).

The SEM analysis of the freeze-dried solids showed apparent differences of the local morphology depending on the freezing methods (Fig. 7). Strands of fine particles were observed in the solids obtained after liquid nitrogen cooling of the varied concentrations of meso-erythritol solutions (Figs. 7A, C, E). Freezing of the solutions on the lyophilizer shelves resulted in agglomerated large particles (Figs. 7B, D, F). Powder XRD analysis of the meso-erythritol solids dried after the different freezing methods showed essentially identical diffraction patterns (e.g., peaks in the same angle), indicating the same stable-form crystals ${ }^{27)}$ (Fig. 8). No new peak was observed in the meso-erythritol primary-dried solid (Fig. 8D). 


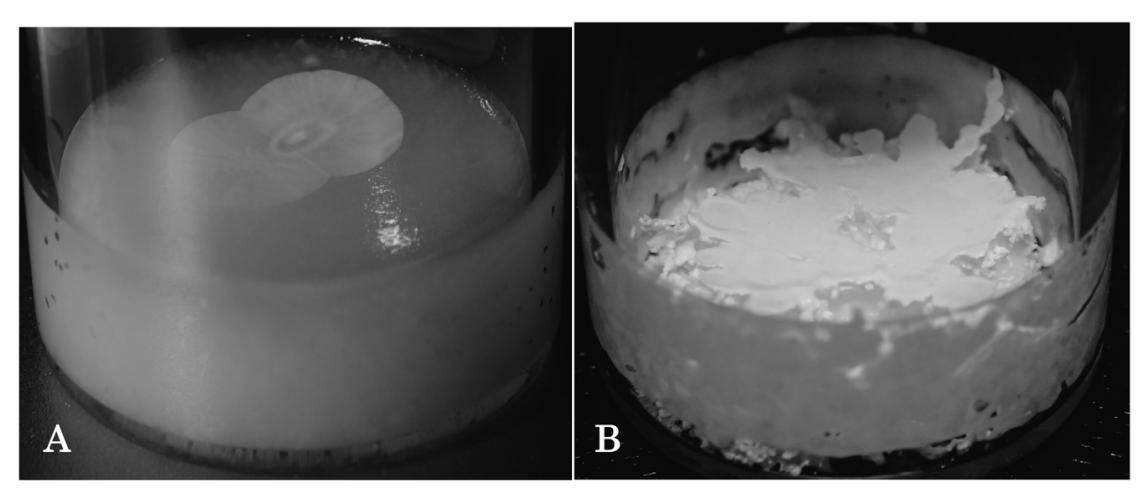

Fig. 6. Effect of Higher-Temperature Shelf-Ramp Cooling $\left(-32^{\circ} \mathrm{C}\right)$ on Appearance of a Shelf-Frozen $m e s o$-Erythritol Solution $(100 \mathrm{mg} / \mathrm{mL})$ before Primary Drying (A) and after Freeze-Drying without Post-Freeze-Heat Treatment (B)
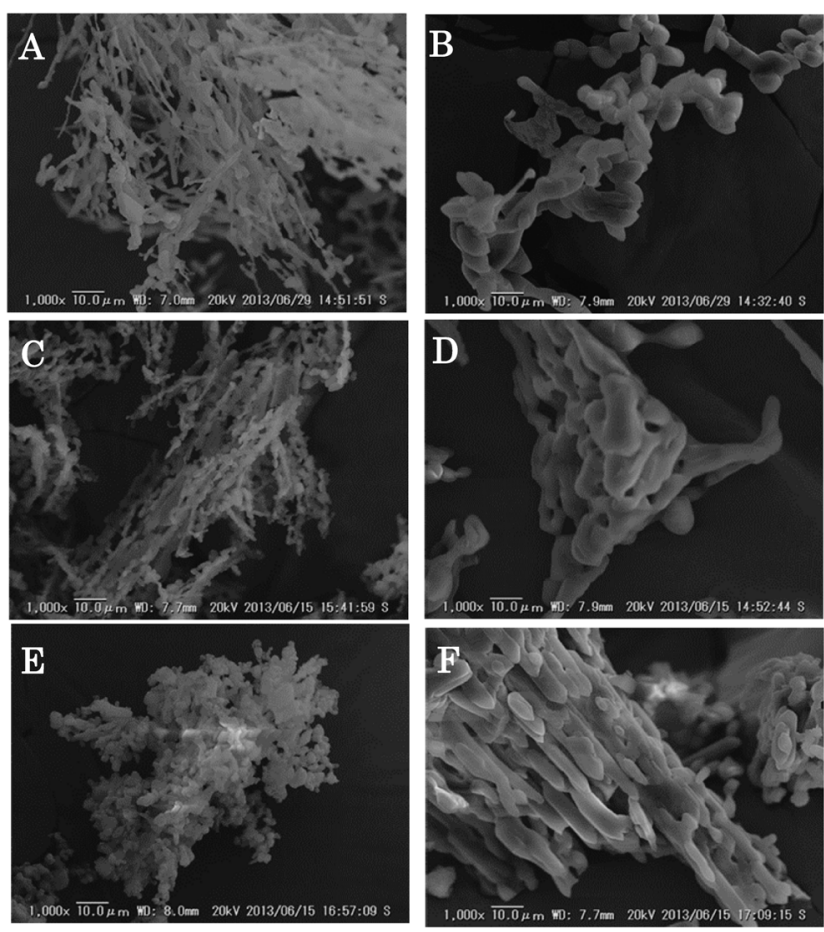

Fig. 7. SEM Images of Lyophilized meso-Erythritol Dried after Freezing of Varied Concentrations of Solutions (A, B: $50 \mathrm{mg} / \mathrm{mL}, C$, D: $100 \mathrm{mg} / \mathrm{mL}, \mathrm{E}, \mathrm{F}: 200 \mathrm{mg} / \mathrm{mL}$ ) by Immersion in Liquid Nitrogen (A, C, E) and Shelf-Ramp Cooling (B, D, F)

This result was confirmed by melting at similar temperatures in thermal analysis (shelf-ramp cooling: $134.9 \pm 1.3^{\circ} \mathrm{C}$, liquid nitrogen cooling: $132.6 \pm 2.1^{\circ} \mathrm{C}$, meso-erythritol reagent powder: $\left.133.2 \pm 1.5^{\circ} \mathrm{C}\right)$.

\section{Discussion}

The high propensity of meso-erythritol to crystallize upon cooling during the heat-melt and in the freezing of aqueous solutions suggests its application as an alternative crystalline bulking agent in freeze-dried formulations. Physical characterization of the frozen solution and experimental freeze-drying demonstrates the importance of process control, particularly the sufficient cooling of the frozen solution required for solute nucleation to obtain the crystalline solids.

Cooling of many frozen aqueous solutions concentrates the non-crystalline solutes (up to $70-80 \%, \mathrm{w} / \mathrm{w}$ ) until the significantly increased viscosity of the non-ice phase prevents fur-

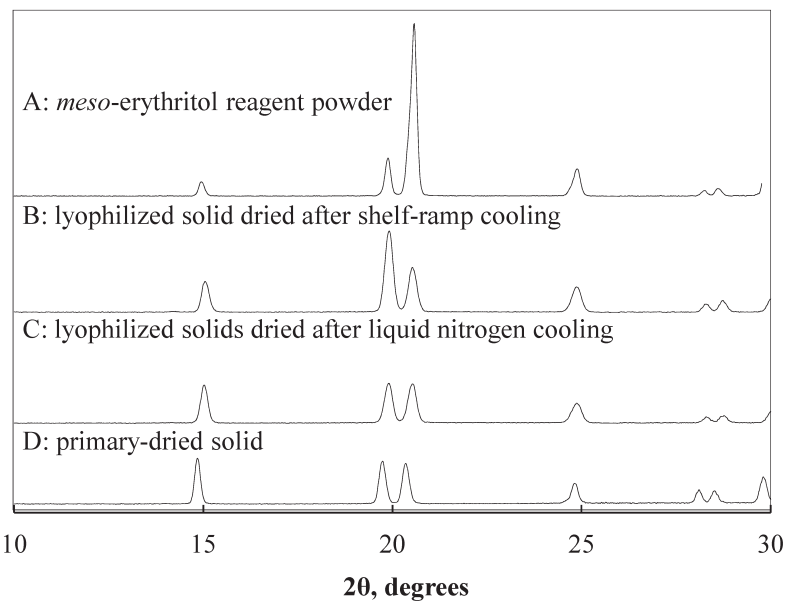

Fig. 8. Powder X-Ray Diffraction Patterns meso-Erythritol Solids

Each line denotes the pattern of (A) meso-erythritol reagent powder, (B) lyophilized solid dried after shelf-ramp cooling, (C) lyophilized solids dried after liquid nitrogen cooling, or (D) primary-dried solids.

ther ice growth at $T_{\mathrm{g}}{ }^{\prime 28,29)}$ Possible substantial freeze-concentration of meso-erythritol by cooling of the frozen solutions to temperatures below $T_{\mathrm{g}}{ }^{\prime}$, either in the DSC cells or in glass vials immersed into liquid nitrogen, could provide reasonable chances to form a large number of the solute nuclei. Increasing mobility of the solute molecules allows rapid growth of the meso-erythritol crystal at around $-40^{\circ} \mathrm{C}$, as observed in the simultaneous XRD-DSC analysis. Additionally, the crystallization process explains the small particulate crystals composing the fine surface appearance solids dried after immersion into liquid nitrogen.

Contrarily, insufficient freeze-concentration of erythritol during cooling of the frozen solution down to $-32^{\circ} \mathrm{C}$ or $-40^{\circ} \mathrm{C}$ should induce only a limited number of the nuclei and growth of the crystal. ${ }^{30)}$ The white dots that appeared in the shelf-frozen solutions, scale-like pattern on the cake surface, and larger crystal size in the SEM images all indicate growth of the solute crystal from a smaller number of nuclei. Starting the vacuum drying before sufficient crystal growth resulted in a partially collapsed solid due to a higher product temperature than $T_{\mathrm{c}}$ of the freeze-concentrated amorphous erythritol region, as observed in the FDM analysis. ${ }^{31-33)}$

The results indicate that meso-erythritol crystallizes as a stable-form anhydride in the freeze-drying process. Absence of the metastable form and/or hydrate crystals is favorable to 
prevent physical changes of the excipient or chemical degradation of co-lyophilized APIs during storage. ${ }^{34,35)}$ The lower crystallization propensity of meso-erythritol, compared with that of mannitol, in the frozen solutions requires process control to obtain microporous crystalline freeze-dried cakes without physical collapse. Shelf-ramp cooling to below $-40^{\circ} \mathrm{C}$ may be performed in many laboratory and manufacturing scale lyophilizers. Prior cooling of the aqueous solutions by immersion in liquid nitrogen is applicable in lyophilization of a small number of vials. How the APIs and other excipients affect the physical property of frozen meso-erythritol solutions remains unclear. Applying process analytical technologies (PAT; e.g., wireless temperature sensors) should reduce the risk of the product quality variation depending on the position of vials on the lyophilizer shelves in a batch or between batches. ${ }^{36)}$ The results confirm superior cake-forming property of mannitol. Observed absence of hydrate crystals suggested use of meso-erythritol as an alternative bulking agent for freeze-drying of APIs that are chemically sensitive to residual water during storage.

\section{Conclusion}

Thermal analysis of various sugars and sugar alcohols showed a high propensity of D-mannitol and meso-erythritol to crystallize from heat-melt and in frozen solutions. Freezedrying of aqueous meso-erythritol solutions after freezing on the lyophilizer shelves and by immersion in liquid nitrogen resulted in varied microstructure solids containing the same crystal-form erythritol. Moreover, the shelf-ramp cooling induced slow nucleation and growth of meso-erythritol crystals in the frozen solutions. Appropriate process control can enable the use of meso-erythritol as an alternative crystalline bulking agent in freeze-dried formulations.

Acknowledgment The authors would like to thank Noboru Kishi of Rigaku Corporation for his support in XRD-DSC system and temperature-controlled XRD system experiments in this study.

Conflict of Interest Kahori Fujii is an employee of POLA Pharma Inc.

\section{References}

1) Liu J., Pharm. Dev. Technol., 11, 3-28 (2006).

2) Chen C., Han D., Cai C., Tang X., J. Control. Release, 142, 299-311 (2010).

3) Nail S. L., Jiang S., Chongprasert S., Knopp S. A., Pharm. Biotechnol., 14, 281-360 (2002).

4) Milton N., Gopalrathnam G., Craig G. D., Mishra D. S., Roy M. L., Yu L., J. Pharm. Sci., 96, 1848-1853 (2007).

5) Carpenter J. F., Prestrelski S. J., Arakawa T., Arch. Biochem. Biophys., 303, 456-464 (1993).

6) Mohammed-Saeid W., Michel D., El-Aneed A., Verrall R., Low N.
H., Badea I., J. Pharm. Pharm. Sci., 15, 548-567 (2012).

7) Al-Hussein A., Gieseler H., J. Pharm. Sci., 101, 2534-2544 (2012).

8) Mehta M., Bhardwaj S. P., Suryanarayanan R., Eur. J. Pharm. Biopharm., 85, 207-213 (2013).

9) Izutsu K., Yoshioka S., Terao T., Chem. Pharm. Bull., 42, 5-8 (1994).

10) Costantino H. R., Curley J. G., Wu S., Hsu C. C., Int. J. Pharm., 166, 211-221 (1998).

11) Akers M. J., Milton N., Byrn S. R., Nail S. L., Pharm. Res., 12, 1457-1461 (1995).

12) Tang X., Pikal M. J., Pharm. Res., 21, 191-200 (2004).

13) Johnson R. E., Kirchhoff C. F., Gaud H. T., J. Pharm. Sci., 91, 914-922 (2002).

14) Mäkinen K. K., Int. J. Dent., 2010, 981072 (2010).

15) EFSA Panel on Food Additives and Nutrient Sources (ANS), EFSA Journal, 8, 1650 (2010).

16) Munro I. C., Bernt W. O., Borzelleca J. F., Flamm G., Lynch B. S., Kennepohl E., Bär E. A., Modderman J., Food Chem. Toxicol., 36, 1139-1174 (1998).

17) Bernt W. O., Borzelleca J. F., Flamm G., Munro I. C., Regul. Toxicol. Pharmacol., 24, S191-S197 (1996).

18) International Pharmaceutical Excipients Council Japan, "Japanese Pharmaceutical Excipients 2007," 41, Yakuji Nippo Limited, Tokyo, Japan, 2007.

19) Gekko K., J. Biochem., 91, 1197-1204 (1982).

20) Tyapkova O., Bader-Mittermaier S., Schweiggert-Weisz U., J. Food Res., 1, 207-217 (2012).

21) Baird J. A., Van Eerdenbrugh B., Taylor L. S., J. Pharm. Sci., 99, 3787-3806 (2010).

22) Chang B. S., Randall C. S., Cryobiology, 29, 632-656 (1992).

23) Uchida T., Takeya S., Phys. Chem. Chem. Phys., 12, 15034-15039 (2010).

24) Malkin T. L., Murray B. J., Brukhno A. V., Anwar J., Salzmann C. G., Proc. Natl. Acad. Sci. U.S.A., 109, 1041-1045 (2012).

25) Morishige K., Yasunaga H., Uematsu H., J. Phys. Chem., 113, 3056-3061 (2009).

26) Cavatur R. K., Vemuri N. M., Pyne A., Chrzan Z., Toledo-Velasquez D., Suryanarayanan R., Pharm. Res., 19, 894-900 (2002).

27) Lopes Jesus A. J., Nunes S. C. C., Silva M. R., Beja A. M., Redinha J. S., Int. J. Pharm., 388, 129-135 (2010).

28) Heller M. C., Carpenter J. F., Randolph T. W., Arch. Biochem. Biophys., 363, 191-201 (1999).

29) Shalaev E. Y., Franks F., Cryobiology, 33, 14-26 (1996).

30) Patel S. M., Bhugra C., Pikal M. J., AAPS PharmSciTech, 10, 14061411 (2009).

31) Meister E., Gieseler H., J. Pharm. Sci., 98, 3072-3087 (2009).

32) Adams G. D. J., Ramsay J. R., J. Pharm. Sci., 85, 1301-1305 (1996).

33) Fonseca F., Passot S., Cunin O., Marin M., Biotechnol. Prog., 20, 229-238 (2004).

34) Hasegawa G., Komasaka T., Bando R., Yoshihashi Y., Yonemochi E., Fujii K., Uekusa H., Terada K., Int. J. Pharm., 369, 12-18 (2009).

35) Yamaki T., Ohdate R., Nakadai E., Yoshihashi Y., Yonemochi E., Terada K., Moriyama H., Izutsu K., Yomota C., Okuda H., Kawanishi T., Chem. Pharm. Bull., 60, 1176-1181 (2012).

36) Wallen A. J., van Ocker S. H., Sinacola J. R., Phillips B. R., J. Pharm. Sci., 98, 997-1004 (2009). 